\title{
THEORY AND CONSTRUCTION OF THE SELF-ACTING SLIDE LATHE,
}

A Paper read before the American Railway Master Mechanics' Association, at the Meeting of the Association, held in Boston, Mass., June, 1872.

By Coleman Seliers, Associate Member.

[Revised for publication in the Journal of the Franklin Institute.]

In compliance with the request to furnish a paper to be read before the American Railway Master Mechanic's Association, at their meeting in Boston, it has occurred to me to present a few thoughts on the theory and construction of that important machine-the selfacting slide lathe.

Prominent in the list of tools for the equipment of the workshop stands the lathe. It was th efirst machine tool; it is the most important. Upon it has been expended much thought, and about it much has been written. My excuse for treating of it is that, during the past few years, the lathe has been much improved; its functions have been carefully studied, and its form changed to agree with the now better known theory of its operation. Traditional shapes and devices have been discarded, and new ones are becoming familiar to the men who work at it.

It must be conceded that the requirements of a good turning lathe are that it must turn a true circle, it must turn a true cylinder, and it must, when facing off, produce a true plane surface. The screw cutting lathe must, in addition to these requirements, produce a sufficiently perfect thread. It is not only necessary that the lathe should finlfil these requirements when new, but it should continue to fulfil them year after year, with the least possible need of adjustment and repair. It has been said that good workmen can do good work with poor tools. Skill and ingenuity may indeed accomplish great results; but the problem of the day is not only how to secure more good workmen, but how to enable such workmen as are at our command to do good work, and how to enable the many really skillful mechanics to accomplish more and better work than heretofore; in other words, the attention of engineers is constantly directed to so perfect machine tools as to utilize unskilled labor.

The turning lathe, being the oldest of all machine tools, has been more hampered by traditional devices and shapes than more recently contrived machines. Changes for the better have to be made, often in opposition to prejudices of the workingmen. This opposition has not, however, deterred engineers from steadily improving the machin- 
ery they design, as new uses and new requiremants seem to demand a change. Much more is required of the turning lathe now than was thought of but a few years ago ; more and better work must be done by it with less skilful workmen, and it must be adapted to the various kinds of work required of it in particular kinds of manufactures. Thus many lathes, adapted to special purposes, have been designed and designated by the names of the classes of work they are intended to accomplish. Through all the various forms of lathes there are certain parts and principles in common, and these parts or principles may be considered without treating of special or unusual forms. Certain general types of the parts of lathes have become as well known by name as any other familiar objects, and mechanics can readily understand the characteristics of these peculiarities when brought to their notice by name only.

Thus, to speak of a lathe shear as a V shear or flat top shear, conveys to those for whom the remarks are intended, a sufficiently clear idea of the two principal forms of the lathe bed or sbear now in use. The V shear has been the favorite in this country for many years; the flat top shear is the rule, not the exception, in England. In view of the well-known fact that durability of machinery is largely dependent upon extended surface, where surfaces move or slide one on another, it is rather surprising that the flat top shear should have met with so little favor in this country up to quite a recent period. Theoretically, it presents the largest wearing surface, and is the most easily made. The saddle of the slide rest, bearing over its whole under surface, may find a support up to the edges of the centre opening of the shear. Having less distance to span unsupported than on the $V$ shear, the saddle can be made thinner and yet strong enough, thus increasing the capacity of the lathe swing over the slide rest. On lathes with V guides there are usually four of these guides, the two outer ones serving as guides for the saddle, and the saddle must, of necessity, span the entire space unsupported from one $V$ to the other; hence it must be thicker and heavier than if resting on a plane surface. The nominal capacity of any lathe is what it will swing over the shear. The actual capacity in relation to cylindrical work is what it will swing over the slide rest; hence the advantage of less thickness in the saddle, if of sufficient strength.

Those workmen who have not used lathes with flat top shears are apt to think that the extended surface in contact with the shear mas make it hard to move. If it be allowed to stick fast with gummy oil Vox, LXIV.-Third Serirs.-No. 2.-Auats', 1872. 
this may be so, but with such care as any machine tool should receive at the hand of the workmen, it is really easier to move. Friction being dependent upon weight not surface, the flat top shear, owing to the extended bearing surface, will permit the use of much lighter saddle, and the dust and dirt is no more apt to catch upon the flat shear surface than on the $V$ shear, and is as effectually pushed off by the saddle. Lightness in the slide rest becomes of great moment on lathes of large capacity, and is worth considering in all lathes.

The flat top shear can be readily planed true on its upper face, on its outer cdges and on its inner edges. The outer edges guide the saddle, lost motions being taken up by shoes or gibs. The lathe heads are guided by the inner edges. The parallelism of all these edges can be readily insured. Convenience in moving requires that the poppet or back head, which (with the flat top shear) is guided by the inner edges of the shear top, should slide easily, and hence should fit loosely. It is of the utmost importance that it shall always hold the same position as to line with the other parts of the lathe when clamped. This suggests the placing of a $\mathrm{V}$ on the under side of one of the inner edges, and thus, by means of the clamping shoe, draw the head always up to the same straight-edge. I consider this combination of a clamping $V$ on the under side of the shear top with the flat surface above it as one of the most important modern improvements on the lathe. The idea originated with Mr. William Sellers, of Philadelphia. It is one of many very advantageous changes made by him, and is the result of many years' study of this important tool.

The function to be performed by the lathe shears or bed is to maintain the driving head or live head spindle in line with the poppet head spindle, and to carry the cutting tool parallel with this centre line. It must do this under various conditions of strain. Screwing up the centre to hold the work, tends to bend the shear in one direction. The strain of the cut tends to bend it in another, in fact, in several directions.

It must be borne in mind that the lathe centres, being above the shear, and dependent entirely on the stiffness of the shear for their rigidity, are placed at some disadvantage in regard to leverage. A clear idea can be obtained of resultant strains if thought be directed to a lathe with a rigidly fixed live head and a very flexible shear. The work, being also rigid, will be driven around its axis by the rotation of the live head spindle, and will therefore tend to turn the 
slide rest, the shear and the poppet head around the axis of rotation, thus producing a severe torsional strain on the bed. Hence the bed must resist strain in all directions; the longer the bed the more elastic it would be in regard to torsion, if it were not for the system of cross-girts introduced in all first-class lathe beds. These cross-girts should cxtend up as far as possible, and form inflexible ties between the two I beams, which represent the sides of the shear. The lead screw in screw-cutting lathes should be placed within the bed, and when supported over its entire length by resting on a trough planed out to receive it, is not subject to deflection, maintaining its right line will produce a truer thread, than if unsupported, except by the nut and end-bearings. By being placed under the shear top, it is entirely protected from falling chips and dirt.

Upon the perfection of workmanship on the spindle of the live head depends the possibility of turning a true circle; upon its freedom from end motions and the exact placement at right angles to it of the line of cross slide of the slide rest, depends the possibility of producing a true plane in facing.

The spindle must be round---truly round-as it will reproduce its own shape in the work being turned. Theoretically, a hardened steel spindle, running in hardened steel bearings, the spindle and bearings being made true after having been hardened, presents the most reliable conditions of correctness and durability. Fortunately, the modern improvements in methods of working hardened steel, furnish means of perfecting this important part of the turning lathe; but to adapt it to the possibility of economical construction, more important changes must be made in form. The customary collars at each end of the journal must be dispensed with, and the front journal of the spindle made truly cylindrical and supported over its entire length by a truly cylindrical bearing. The back bearing may be conical, and one stationary ring or collar of hardened steel secured to the spindle back of the back bearing, may be ground true and be made to run between hardened steel plates without any lost motion whatever, and no liability to stick or jam. This form of back thrust does away entirely with the tail screw, presents a more extended and durable wearing surface, and permits the spindle to be extended through the back support, and thus receive change wheels of any size for screw cutting or feed. The form of the live head-stock should be such as to hold the front bearing in a rigid manner against lateral strains, and the back bearing against a strain of the spindle pressed endways. 
The cone speeds should be so proportioned to the gearing on backgeard and tripple-geared lathes as to insure an exact ratio of change from the fastest to the slowest speed in each and every change,that is, with five lifts to the cone in a tripple-geared lathe, 15 speeds should be possible, each proportionately slower than the one next to it. The cone pulley or spindle should be of iron turned inside and out so as to be perfectly balanced, and should, in its inner sleeve, present an extended bearing upon the spindle capable of proper lubrication. The spindle should be of the best cast-steel, and being first roughed out, should be hardened and then reduced to proper shape and size by suitable machinery. The taper hole for the live centre should be finished true after the spindle is made true on the outside. The truth of this hole is just as important as the accuracy of the outside of the spindle. Upon its absolute concentricity with the outside of spindle depends the possibility of the centre point running true, no matter how replaced after it has been taken out.

Too much care cannot be taken with the manufacture of this important part of the machine. Hardened steel spindles have been made in this manner for lathes as large as $48^{\prime \prime}$ swing, the front journal of such a lathe being 5 inches in diameter; but the practical difficulties in the way of working with safety such large masses of hardened steel, prevents its adoption for spindles over about three inches in diameter.

On all double-geared lathes the face plates should be made to unscrew for convenience of changing to various sizes and the ready application of chucking devices. The overhanging end of the lathe spindle to receive the face plate should always have a portion of its length next to the shoulder, cylindrical without any screw thread. The screw on the end may be short and should fit loosely in the face plate; but a careful fit should be made in the face plate of the part carried by the plane part of the spindle, and the shoulder against which the nut of the face plate abuts should be made very true. This arrangement insures the face plates always running true, no matter how frequently they are changed, nor how loosely the screw may fit, provided they are not bruised or injured in the fitting parts.

I would here remark that spindles made as described have been tested during many years' constant hard usage, and have been found to show no appreciable wear. Possible abjustment of all wearing parts should be provided, but such adjustment should not be at the convenience or whim of the workman using the machine, as is the 
case with the spindle collared at its journals and provided with a tail screw for the back thrust. I have already mentioned the method of bolding the poppet head so as to insure its alignment by means of the $\mathrm{V}$ on the under side of the flat top shear. Its spindle should be carefully fitted, and a device recently patented by Mr. Faught, with A. Whitney \& Son, Philada., is of great use in insuring stability. He clamps the spindle at the extreme end of the bearing by means of a split conical sleeve forced in by a screw, which takes up all lost motions or play and insures its central position. If lathes were not required to turn tapers as well as cylinders, there can be no doubt that the poppet head, made in one piece, resting on the shears over a sufficiently broad surface and capable of adjustment sideways only to the extent of practical alignment, would be the simplest and the best. In our own practice we prefer this system, and adapt to lathes requiring it a device which enables the turning tool to be guided by former bars, and thus to produce tapers or irregular shapes, such as the curves of handles, \&c. This device, called technically " a former" attachment," does much better conical or tapered work than with the centre set over out of line for reasons too obvious to all mechanics familiar with the use of the machine, and gives a greater range to its capacity. I may be pardoned for mentioning in this relation what we consider the readiest method of bringing the centre in line after the head has been set over, in adjusting the centres in the first place, or in testing the correctness of a new lathe. A bar of round iron carefully centered, is turned up a short distance on one end. This turned end being placed next to the live head centre, a turning tool clamped in the slide rest is made to just touch the turned part. Tiking out the bar, the tool is then moved over to the poppet head spindle, and the bar reversed with its turned end next to poppet head centre, when, if the tool just touches the turned part as before, the lathe may be considered in adjustment.

A vertical adjustment to the point of the turning tool is of the utmost importance in lathes and for turning work of small diameter. The larger the diameter of the work to be turned, the less need of such adjustment; in other words, the more latitude there may be in the position of the tool point. Lathes of $16^{\prime \prime}$ swing and under should be provided with some means of raising or depressing the point of the tool. Large lathes, where the rests are compounded, may dispense with this. The feed for turning should be independent of the feed for serew cutting. The changes of speed to the feed for turning 
should be capable of gradation to suit the nature of the work between the extremes of speed. When (as is the case in large lathes, ) there is an automatic cross feed provided, the various feeds should be so arranged as to be readily changed from one to the other. Having set in gear any one of the feeds, it should be stopped and started by one and the same motion for all the feeds. Such motions as screwing up the spindle of the poppet head, stopping and starting feeds, setting up the slide rests, \&c., are motions of habit, and should, if possible, be uniform on all lathes. This is especially the case where two kinds of feed are operated by the same starting gear. No complication of motions should embarrass the workman. There should be no hesitation on the part of the workman as to which way he should move the starting gear in any case. The cross slide of the slide-rest, in fact, all the slides of the rest, should be so made as to entirely cover their sliding surface, and thus exclude all dirt. This is of the utmost importance, and too often neglected by makers of otherwise very good lathes.

For lathes up to $36^{\prime \prime}$ swing the very convenient single screw tool post can be used to advantage; but for larger lathes it is not possible to hold the tool in this manner alone, if the lathe is proportionally powerful. Four screws or standing belts with clamp plates serve a better purpose and admit of a greater range of tool positions.

What I have thus presented in relation to the prominent features of the self-acting slide lathe is, in reality, the result of many years' observation and study of this important tool by some of the best engineers and noted by me during a somewhat extended familiarity with the tool as a workman and designer of tools. A turning lathe, as of all other machines, should not be made up of a collection of conventional forms and devices without any good argument to recommend their use. It should be capable of analysis, and each and every part should be constructed with a view to the end to be obtained. Workmen, when testing tools so constructed, are soon convinced of the advantage. Railway master mechanics have better opportunities of examining into the merits of machine tools than many others, and are ever the readiest to appreciate improvements $I_{t}$ is with great pleasure, therefore, I present these observations to them and hope they may at least suggest thought, and aid them to inquiry into the merits of the tool so constructed. 